\title{
PERAN DAN IMPELEMENTASI STRATEGI PENGEMBANGAN DISBUDPAR KAB. SUMBA TENGAH PROVINSI NTT DALAM PEMBANGUNAN PARIWISATA (SUATU PENDEKATAN KUALITATIF)
}

Yelince Rambu Roku a, 1 , I Gst. Agung Oka Mahagangga a, 2

1ramburokuyelin@gmail.com, ${ }^{2}$ ragalanka@gmail.com

a Program Studi S1 Destinasi Pariwisata,Fakultas Pariwisata,Universitas Udayana, Jl. Dr. R. Goris, Denpasar, Bali 80232 Indonesia

\section{ABSTRACT}

Facts indicate the potential of tourism in the Central Sumba Regency has not been able to attract tourist arrivals. The role stakeholders, especially SKPD Department of Culture and tourism (Disbudpar) Central Sumba Regency have a heavy duty to make tourism development. The method used was a case study approach (inductive) using qualitative methods. Data were analyzed using qualitative data analysis techniques with presentation techniques qualitative descriptive data. The results of this research are the role Disbudpar Kab. Central Sumba in tourism development constrained human resources issues and other findings are necessary translation of roles more effectively and efficiently with attention to personal ability, social skills and intellectual abilities in the future culture. The next finding is the difficulty Disbudpar Kab. Central Sumba in the implementation of the work plan caused by many factor. It is important to consider in the future development of tourism is the attention to the internal and external coordination and the determination of the potential market rating that will facilitate the development of tourism attractions such as the establishment or featured travel products and preparation of human resources, infrastructure and other supporting facilities.

Keywords: Strategy, Implementation, Strategy, Development, Tourism

\section{PENDAHULUAN}

\subsection{Latar Belakang}

Kabupaten Sumba Tengah Provinsi Nusa Tenggara Timur (NTT) adalah kabupaten baru hasil pemekaran dari Kabupaten Sumba Barat yang berada di wilayah administratif Provinsi Nusa Tenggara Timur. Langkah awal dari pengembangan kepariwisataan di Kabupaten Sumba Tengah yang oleh Dinas Kebudayaan dan Pariwisata Kabupaten Sumba Tengah yaitu pariwisata budaya, hal ini sesuai dengan pembagian wilayah (cluster) oleh Dinas Pariwisata Ekonomi dan Kreatif Provinsi Nusa Tenggara Timur yang memasukkan Pulau Sumba sebagai tujuan pengembangan obyek wisata budaya.

Namun hingga saat ini kunjungan wisatawan ke Kabupaten Sumba Tengah belum dirasakan sesuai dengan harapan. Padahal diyakini Kabupaten Sumba Tengah memiliki banyak potensi budaya dan potensi alam. Berikut tabel 1.1 jumlah kunjungan wisatawan ke kab. Sumba tengah dalam kurun waktu 5 tahun terakhir .

Tabel 1.1

Jumlah Kunjungan Wisatawan Lima Tahun

Terakhir

\begin{tabular}{|c|c|c|c|c|}
\hline \multirow{2}{*}{ No } & \multirow{2}{*}{ Tahun } & \multicolumn{2}{|c|}{ Jumlah Kunjungan } & Total \\
\cline { 3 - 5 } & & Wisman & Wisnus & \\
\hline 1 & 2010 & 80 & 45 & 125 \\
\hline 2 & 2011 & 95 & 53 & 148 \\
\hline 3 & 2012 & 136 & 78 & 214 \\
\hline
\end{tabular}

\begin{tabular}{|l|l|l|l|l|}
\hline 4 & 2013 & 300 & 150 & 450 \\
\hline 5 & 2014 & 440 & 200 & 640 \\
\hline
\end{tabular}

Sumber : Disbudpar Kabupaten Sumba Tengah, 2015

Dari tabel $1.1 \mathrm{di}$ atas tampak angka kunjungan wisatawan ke kab. Sumba Tengah didominasi oleh wisatawan mancanegara dengan jumlah tertinggi di tahun 2014 sebanyak 440 orang. Suatu angka yang masih minim jika melihat besarnya potensi budaya dan potensi alam yang dimiliki Kab. Sumba Tengah. Berikut pada tabel 1.2 di bawah disajikan daya tarik wisata unggulan di Kab. Sumba Tengah :

\section{Tabel 1.2}

Daya Tarik Wisata di Kab. Sumba Tengah

\begin{tabular}{|c|l|l|}
\hline No & $\begin{array}{l}\text { Nama Obyek } \\
\text { Wisata }\end{array}$ & \multicolumn{1}{|c|}{ Lokasi } \\
\hline 1 & $\begin{array}{l}\text { Air Terjun } \\
\text { Praikalala }\end{array}$ & $\begin{array}{l}\text { Kec.amatan Umbu Ratu Nggay } \\
\text { Barat }\end{array}$ \\
\hline 2 & $\begin{array}{l}\text { Air Terjun } \\
\text { Waikapori }\end{array}$ & $\begin{array}{l}\text { Desa Maradesa Selatan } \\
\text { Kecamatan Umbu Ratu Nggay }\end{array}$ \\
\hline 3 & $\begin{array}{l}\text { Air Terjun } \\
\text { Matayangu }\end{array}$ & $\begin{array}{l}\text { Desa Manurara Kecamatan } \\
\text { Katikutana Selatan }\end{array}$ \\
\hline 4 & $\begin{array}{l}\text { Air Terjun } \\
\text { Bola }\end{array}$ & $\begin{array}{l}\text { Desa Wangga Waiyengu } \\
\text { Kecamatan Umbu Ratu Nggay } \\
\text { Barat Kecamatan }\end{array}$ \\
\hline 5 & $\begin{array}{l}\text { Air Terjun Ta } \\
\text { Urang }\end{array}$ & $\begin{array}{l}\text { Desa Manurara, Ke } \\
\text { Katikutana Selatan }\end{array}$ \\
\hline 6 & $\begin{array}{l}\text { Pantai } \\
\text { Karendi }\end{array}$ & $\begin{array}{l}\text { Desa Susu Wendewa } \\
\text { Kecamatan Mamboro }\end{array}$ \\
\hline 7 & $\begin{array}{l}\text { Pantai Pahar / } \\
\text { Wende }\end{array}$ & $\begin{array}{l}\text { Desa Lenang Kecamatan } \\
\text { Umbu Ratu Nggay }\end{array}$ \\
\hline 8 & Pantai Kapulit & $\begin{array}{l}\text { Desa Watuasa Kecamatan } \\
\text { Mamboro }\end{array}$ \\
\hline
\end{tabular}


Vol. 4 No 2, 2016

\begin{tabular}{|c|c|c|}
\hline No & $\begin{array}{l}\text { Nama Obyek } \\
\text { Wisata }\end{array}$ & Lokasi \\
\hline 9 & $\begin{array}{l}\text { Pantai Tarapa } \\
\text { dan pasir besi }\end{array}$ & $\begin{array}{l}\text { Desa Manuwolu Kecamatan } \\
\text { Mamboro }\end{array}$ \\
\hline 10 & Pantai Maloba & $\begin{array}{lr}\text { Desa Konda } & \text { Maloba } \\
\text { Kecamatan } & \text { Katikutana } \\
\text { Selatan } & \end{array}$ \\
\hline 11 & $\begin{array}{l}\text { Pantai } \\
\text { Mananga }\end{array}$ & $\begin{array}{lcc}\text { Desa } \quad \text { Wendewa } & \text { Utara } \\
\text { Kecamatan Mamboro } & \end{array}$ \\
\hline 12 & Pantai Aili & $\begin{array}{lr}\text { Desa Konda } & \text { Maloba } \\
\text { Kecamatan } & \text { Katikutana } \\
\text { Selatan } & \\
\end{array}$ \\
\hline 13 & Pantai Konda & $\begin{array}{lr}\text { Desa Konda } & \text { Maloba } \\
\text { Kecamatan } & \text { Katikutana } \\
\text { Selatan } & \\
\end{array}$ \\
\hline 14 & $\begin{array}{l}\text { Pantai } \\
\text { Waiurang }\end{array}$ & Kecamatan Umbu Ratu Nggay \\
\hline 15 & $\begin{array}{ll}\text { Gua } & \text { Alam } \\
\text { Liangu } & \\
\text { Marapu } & \\
\end{array}$ & $\begin{array}{l}\text { Desa Umbu Pabal Kecamatan } \\
\text { Umbu Ratu Nggay Barat }\end{array}$ \\
\hline 16 & $\begin{array}{l}\text { Gua Alam } \\
\text { Tana Rara }\end{array}$ & $\begin{array}{l}\text { Desa Mara Desa Kecamatan } \\
\text { Umbu Ratu Nggay }\end{array}$ \\
\hline 17 & $\begin{array}{l}\text { Gua } \\
\text { Liangu Paniki }\end{array}$ & $\begin{array}{l}\text { Desa Wailawa Kecamatan } \\
\text { Katikutana Selatan }\end{array}$ \\
\hline 18 & $\begin{array}{l}\text { Gua Alam Rati } \\
\text { Maka Dewa }\end{array}$ & $\begin{array}{l}\text { Desa Dameka Kecamatan } \\
\text { Katikutana Selatan }\end{array}$ \\
\hline 19 & $\begin{array}{l}\text { Kampung } \\
\text { Adat } \\
\text { Wawarongu }\end{array}$ & $\begin{array}{lcc}\text { Desa } & \text { Wendewa } & \text { Barat } \\
\text { Kecamatan Mamboro } & \end{array}$ \\
\hline 20 & $\begin{array}{l}\text { Kampung } \\
\text { Adat Manua } \\
\text { Kalada } \\
\end{array}$ & $\begin{array}{lll}\text { Desa } & \text { Wendewa } & \text { Selatan } \\
\text { Kecamatan Mamboro } & \end{array}$ \\
\hline 21 & $\begin{array}{l}\text { Kampung } \\
\text { Adat } \\
\text { Laitarung }\end{array}$ & $\begin{array}{l}\text { Desa Makatakeri Kecamatan } \\
\text { Katikutana }\end{array}$ \\
\hline 22 & $\begin{array}{l}\text { Kampung } \\
\text { Adat } \\
\text { Kabonduk } \\
\end{array}$ & $\begin{array}{l}\text { Desa Makatakeri Kecamatan } \\
\text { Katikutana }\end{array}$ \\
\hline 23 & $\begin{array}{l}\text { Kampung } \\
\text { Adat Pasunga }\end{array}$ & $\begin{array}{l}\text { Desa Anakalang Kecamatan } \\
\text { Katikutana }\end{array}$ \\
\hline 24 & $\begin{array}{l}\text { Kampung } \\
\text { Adat } \\
\text { Anakalang, } \\
\text { Waikajawi } \\
\end{array}$ & $\begin{array}{l}\text { Desa Anakalang Kecamatan } \\
\text { Katikutana }\end{array}$ \\
\hline 25 & $\begin{array}{l}\text { Kampung } \\
\text { Adat Galu } \\
\text { Bakul dan } \\
\text { sekitarnya } \\
\text { (Kabelawuntu, } \\
\text { Anabura, } \\
\text { Matolang dan } \\
\text { Radak) } \\
\end{array}$ & $\begin{array}{l}\text { Desa Malinjak Kecamatan } \\
\text { Katikutana Selatan }\end{array}$ \\
\hline 26 & $\begin{array}{l}\text { Kampung } \\
\text { Adat Padabar }\end{array}$ & $\begin{array}{l}\text { Desa Waimanu Kecamatan } \\
\text { Katikutana Selatan }\end{array}$ \\
\hline 27 & $\begin{array}{l}\text { Kampung } \\
\text { Adat } \\
\text { Laipatedang }\end{array}$ & $\begin{array}{l}\text { Desa Makatakeri Kecamatan } \\
\text { Katikutana }\end{array}$ \\
\hline 28 & $\begin{array}{l}\text { Kampung } \\
\text { Adat Anajiaka } \\
\text { Ngora }\end{array}$ & $\begin{array}{l}\text { Desa Anajiaka Kecamatan } \\
\text { Umbu Ratu Nggay Barat }\end{array}$ \\
\hline 29 & $\begin{array}{l}\text { Kampung } \\
\text { Adat } \\
\text { Manukaka } \\
\end{array}$ & $\begin{array}{l}\text { Desa Wairasa Kecamatan } \\
\text { Umbu Ratu Nggay Barat }\end{array}$ \\
\hline
\end{tabular}

\begin{tabular}{|c|c|c|}
\hline No & $\begin{array}{l}\text { Nama Obyek } \\
\text { Wisata }\end{array}$ & Lokasi \\
\hline 30 & $\begin{array}{l}\text { Kampung } \\
\text { Adat } \\
\text { Anamadiata }\end{array}$ & $\begin{array}{l}\text { Desa Anajiaka Kecamatan } \\
\text { Umbu Ratu Nggay Barat }\end{array}$ \\
\hline 31 & $\begin{array}{l}\text { Kampung } \\
\text { Adat } \\
\text { Praikalowu }\end{array}$ & $\begin{array}{l}\text { Desa Wailawa Kecamatan } \\
\text { Katikitana Selatan }\end{array}$ \\
\hline 32 & $\begin{array}{l}\text { Kampung } \\
\text { Adat } \\
\text { Kambajawa }\end{array}$ & $\begin{array}{l}\text { Desa Umbu Pabal Kecamatan } \\
\text { Umbu Ratu Nggay Barat }\end{array}$ \\
\hline 33 & $\begin{array}{l}\text { Kampung } \\
\text { Adat } \\
\text { Wailolung } \\
\end{array}$ & $\begin{array}{l}\text { Desa Anajiaka Kecamatan } \\
\text { Umbu Ratu Nggay Barat }\end{array}$ \\
\hline 34 & $\begin{array}{l}\text { Kampung } \\
\text { Adat Bolu } \\
\text { Bokat }\end{array}$ & $\begin{array}{l}\text { Desa Mara Desa Kecamatan } \\
\text { Umbu Ratu Nggay }\end{array}$ \\
\hline 35 & $\begin{array}{l}\text { Kampung } \\
\text { Adat Marada } \\
\text { Deta }\end{array}$ & $\begin{array}{l}\text { Desa Mara Desa Kecamatan } \\
\text { Umbu Ratu Nggay }\end{array}$ \\
\hline 36 & $\begin{array}{l}\text { Makam Umbu } \\
\text { Tipuk Marisi }\end{array}$ & $\begin{array}{l}\text { Desa Anajiaka Kecamatan } \\
\text { Umbu Ratu Nggay Barat }\end{array}$ \\
\hline 37 & $\begin{array}{l}\text { Embung } \\
\text { Lokujangi }\end{array}$ & $\begin{array}{l}\text { Perbatasan antara Desa Umbu } \\
\text { Pabal Selatan Kecamatan } \\
\text { Umbu Ratu Nggay Barat dan } \\
\text { Desa Dasa Elu Kecamatan } \\
\text { Katikutana Selatan }\end{array}$ \\
\hline 38 & $\begin{array}{l}\text { Wisata } \\
\text { Kuliner } \\
\text { Langgaliru }\end{array}$ & $\begin{array}{l}\text { Desa Padiratana Kecamatan } \\
\text { Umbu Ratu Nggay }\end{array}$ \\
\hline
\end{tabular}

Sumber : Disbudpar, 2014

Daya tarik wisata di atas belum termasuk event-event adat seperti upacara kampung adat yang rutin diselenggarakan setiap tahun dan yang diselenggarakan oleh pemerintah daerah.

Tulisan ini menyajikan hasil penelitian lapangan yang ingin memahami peran dan implementasi strategi pengembangan oleh Disbudpar Kab. Sumba Tengah dalam pembangunan pariwisata. Temuan dalam tulisan ini diharapkan mampu memberikan solusi-solusi bagi Disbudpar Kab. Sumba Tengah yang bertindak sebagai pemegang kebijakan dan fasilitator pembangunan kepariwisataan.

\subsection{Rumusan Masalah}

1. Apa Peran Dinas Kebudayaan dan Pariwisata (Disbudpar) dalam Pengembangan Pariwisata di Kabupaten Sumba Tengah, Provinsi Nusa Tenggara Timur?

2. Bagaimana Implementasi Strategi Pengembangan Pariwisata Dinas Kebudayaan dan Pariwisata (Disbudpar) Kabupaten Sumba Tengah, Provinsi Nusa Tenggara Timur? 


\subsection{Tujuan dan Manfaat}

Berdasarkan rumusan masalah di atas yang menjadi tujuan dari penelitian ini adalah :

1. Untuk mengetahui Peran Dinas Kebudayaan dan Pariwisata dalam Pengembangan Pariwisata di Kabupaten Sumba Tengah Provinsi NTT.

2. Untuk memahami Implementasi Strategi Pengembangan Pariwisata yang dilakukan oleh Dinas Kebudayaan dan Pariwisata Kabupaten Sumba Tengah Provinsi NTT.

Adapun manfaat yang diperoleh dari tulisan ini adalah manfaat akademis sebagai terapan ilmu pariwisata khususnya mata kuliah Perencanaan Destinasi Wisata dan mata kuliah kebijakan pariwisata termasuk mata kuliah metode penelitian. Manfaat Praktis tulisan ini dapat memberikan pemahaman dan solusi pembangunan pariwisata Kab. Sumba Tengah melalui peran dan implementasi strategi pengembangan Disbudpar Kab. Sumba Tengah yang lebih efisien dan efektif kedepannya.

\section{TINJAUAN PUSTAKA}

Tinjauan pustaka sebelumnya baik secara fokus maupun lokus adalah laporan akhir D4 Pariwisata, Fak. Pariwisata Unud, yang dilakukan oleh Agus Wikanatha (2010) yang berjudul "Peran Disparda Provinsi Bali dalam Recovery Pariwisata Pasca bom Bali", laporan akhir D4 Pariwisata Fak. Pariwisata Unud, oleh Yeremias Otmard Dewa dalam skripsi D4 Pariwisata Fakultas Pariwisata (2011) berjudul,"Pariwisata Kampung Tradisional Wogo di Kabupaten Ngada Provinsi Nusa Tenggara Timur (Kajian Sosial Budaya Terhadap Pengembangan Daya Tarik Wisata)" dan Skripsi Program Studi S1 Destinasi Pariwisata, Fak. Pariwisata Unud, Andryano Febrian Bambar (2015) berjudul "Perencanaan Fasilitas Pariwisata di Kampung Wae Rebo, Desa Satarlenda, Kabupaten Manggarai Tengah, Nusa Tenggara Timur". Konsep yang digunakan untuk memperjelas dan sebagai acuan dalam penelitian ini terdapat satu teori dan beberapa konsep yaitu konsep pariwisata (Yoeti, 1992), Teori Struktural-Fungsional (Sanderson, 1993), konsep peran (Soekanto 1993), konsep strategi (Lawrence R. Jauch dan W.F. Glueck dalam Purwanto, 2012), dan konsep pengembangan pariwisata (Pendit, 2006).

\subsection{Lokasi Penelitian}

Penelitian tentang Peran Dinas Kebudayaan dan Pariwisata Kabupaten Sumba Tengah, Provinsi Nusa Tenggara Timur Dalam Pembangunan Pariwisata (Studi Kasus Strategi Pengembangan Pariwisata) dilaksanakan di Dinas Kebudayaan dan Pariwisata yang berlokasi di Kompleks Pemerintahan Makatul, Kota Waibakul, Kabupaten Sumba Tengah.

\subsection{Ruang Lingkup Penelitian}

Ruang lingkup penelitian adalah sebagai berikut :

1. Peran Dinas Pariwisata sebagai pemangku kebijakan dan fasilitator dalam pengembangan pariwisata di Kabupaten Sumba Tengah yang tertuang dalam tugas pokok dan fungsi Dinas Kebudayaan dan Pariwisata Kabupaten Sumba Tengah, Provinsi Nusa Tenggara Timur ditinjau dari :
A. Aspek perumusan kebijakan
B. Pelayanan
C. Pemberdayaan
D. Solusi Permasalahan di Masyarakat
E. Pengelolaan Asset Daerah

2. Implementasi strategi pengembangan yang dimaksud dalam penelitian ini adalah penetapan :
A. Misi,
B. Tujuan,
C. Sasaran
D. Strategi,
E. Arah kebijakan,

Sebagai upaya mewujudkan pembangunan pariwisata melalui program-program kerja masing-masing bidang terkait operasional teknis lapangan Disbudpar Kabupaten Sumba Tengah, Provinsi NTT yaitu Bidang Kebudayaan, Bidang Kesenian, Bidang Pemasaran dan Penyuluhan Pariwisata dan Bidang Pengembangan Produk Wisata.

\section{METODOLOGI PENELITIAN}

Penelitian ini merupakan penelitian kualitatif dengan menggunakan jenis data yaitu kualitatif dan data kuantitatif (Soegiono, 2004) termasuk sumber data data primer dan data sekunder (Arikunto, 2010).

Teknik pengumpulan data yang digunakan adalah observasi partisipasi (Rahayu dkk, 2004), 
wawancara mendalam (Bungin, 2003), dan Studi

Kepustakaan (Bungin, 2003).

Teknik penentuan informan menggunakan Purpossive Sampling (Kusmayadi dan Sugiarto, 2000) sebagai informan pangkal adalah Kadisbudpar. Kab Sumba Tengah dan informan kunci adalah 4 orang Kabid dan 2 orang staf di lingkungan Disbudpar. Kab. Sumba Tengah.

Teknik analisis data dalam tulisan ini adalah teknik analisis data kualitatif (Bogdan dan Biklen dalam Moleong, 2005). Mengingat keterbatasan halaman dalam penulisan jurnal ini hasil penelitian disederhanakan, sehingga kutipan-kutipan hasil wawancara tidak dicantumkan namun dideskripsikan yang sudah memuat interpretasi penulis sebagai ciri khas penelitian kualitatif.

\section{HASIL DAN PEMBAHASAN.}

\subsection{Gambaran Umum Lokasi Penelitian}

Secara geografis Kabupaten Sumba Tengah di Provinsi Nusa Tenggara Timur, terletak di garis tengah Pulau Sumba, dimana membentang dari pantai Utara hingga pantai Selatan pulau Sumba. Secara astronomis, wilayah Kabupaten Sumba Tengah terbentang diantara $9^{\circ} 18^{\prime}-10^{\circ} 20^{\prime}$ Lintang Selatan; $118^{\circ} 15^{\prime}$ - $120^{\circ} 23^{\prime}$ Bujur Timur. Ibu kotanya adalah Waibakul, dengan batas-batas wilayah sebagai berikut:

1. Sebelah Utara berbatasan dengan Selat Sumba

2. Sebelah Selatan berbatasan dengan Samudera Hindia

3. Sebelah Timur berbatasan dengan Kecamatan Lewa dan Kecamatan Hahar di wilayah Kabupaten Sumba Timur

4. Sebelah Barat berbatasan dengan Kecamatan Wanokaka, Kecamatan Loli dan Kecamatan Tana Righu di wilayah Kabupaten Sumba Barat
Gambar 4.1

Peta Kab. Sumba Tengah

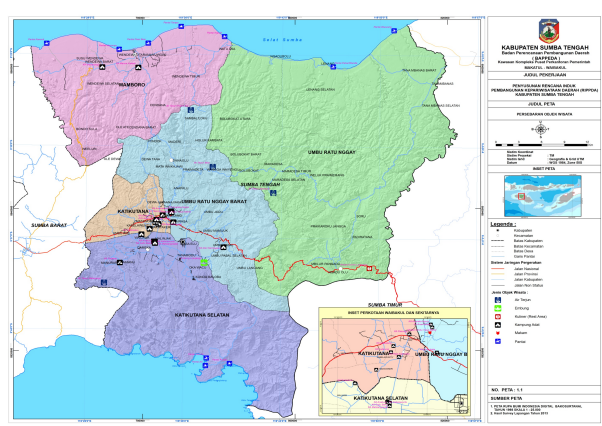

Sumber : Bappeda Kab. Sumba Tengah, 2013

Berdasarkan gambar $4.1 \mathrm{di}$ atas dapat dilihat letak dan keadaan geografis kabupaten Sumba Tengah Provinsi NTT dengan berbagai potensi pariwisata yang dimiliki. Wilayah administrasi Kabupaten Sumba Tengah meliputi 5 wilayah kecamatan, yang terbagi dalam 65 desa.

4.2 Peran Dinas Kebudayaan dan Pariwisata (Disbudpar) dalam Pengembangan Pariwisata di Kabupaten Sumba Tengah,Provinsi Nusa Tenggara Timur (NTT) .

Dinas Kebudayaan dan Pariwisata Kabupaten Sumba Tengah merupakan unsur pelaksana Pemerintah Kabupaten Sumba Tengah, yang berada di bawah dan bertanggung jawab kepada Bupati Sumba Tengah. Sebagai Satuan Kerja Perangkat Daerah (SKPD), Kantor Dinas Kebudayaan dan Pariwisata (Disbudpar) Kabupaten Sumba Tengah Provinsi Nusa Tenggara Timur (NTT) memiliki tugas utama sebagai regulator dan fasilitator dengan ruang lingkup Kebudayaan dan Pariwisata di Kabupaten Sumba Tengah (Renstra Disbudpar Sumba Tengah, 2014-2018).

Berdasarkan ruang lingkup pelayanan Satuan Kerja Perangkat Daerah (SKPD) Kebudayaan dan Pariwisata (Disbudpar) Kabupaten Sumba Tengah di atas yaitu kebudayaan dan pariwisata maka SKPD Disbudpar Kabupaten Sumba Tengah memiliki Tugas Pokok dan Fungsi (Tupoksi) sebagai berikut (Renstra Disbudpar Kab. Sumba Tengah 2014-2018) yaitu Penyelenggaraan kewenangan Pemerintah Kabupaten dalam rangka desentralisasi di bidang Kebudayaan dan Pariwisata.

Secara umum peran Disbudpar Kab. Sumba Tengah dalam pengembangan pariwisata sesuai Tupoksi dimulai dari Kepala Dinas sebagai 
pimpinan lembaga, sekretaris membawahi bagian kesekretariatan, dan Kepala Bidang terdiri dari Bidang Kebudayaan, Bidang Kesenian, Bidang Pemasaran dan Penyuluhan Pariwisata dan Bidang Pengembangan Produk Wisata.

\section{Tabel 4.1}

Struktur Organisasi Disbudpar Kab. Sumba Tengah

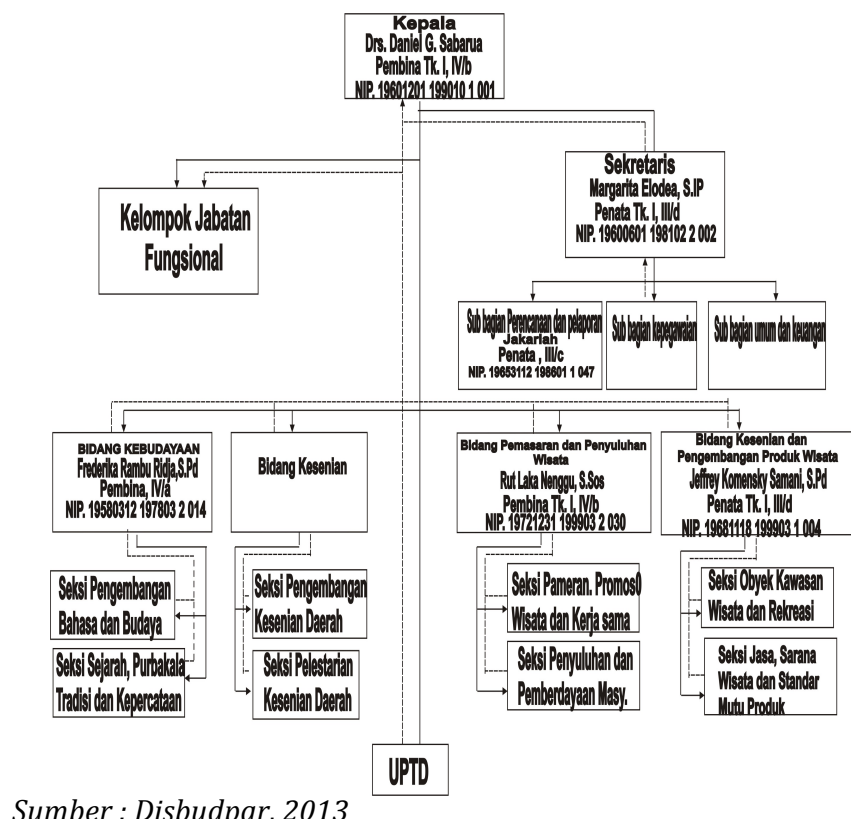

Sumber : Disbudpar, 2013

Berdasarkan tabel dan gambar di atas dan tampak secara kuantitas keterbatasan SDM yang dimiliki Kantor Dinas Kebudayaan dan Pariwisata Kabupaten Sumba Tengah, Provinsi Nusa Tenggara Timur. Total jumlah SDM adalah sebanyak 21 orang termasuk pimpinan SKPD atau diseut Kepala Dinas. Dapat dibayangkan antara kebutuhan dan tenaga yang ada belum dapat dikatakan atau masih jauh dari kata memadai sebagai suatu organisasi pelayanan kepada masyarakat di sektor pariwisata.

Secara hierarkhis struktur organisasi Kantor Dinas Kebudayaan dan Pariwisata, Provinsi NTT tidak berbeda dengan organisasi pemerintahan pada umumnya hanya saja tenaga SDM yang dimiliki sangat sedikit dengan uraian tugas atau job desk yang padat. Temuan penelitian menunjukkan secara kuantitas keterbatasan SDM yang dimiliki Kantor Dinas Kebudayaan dan Pariwisata Kabupaten Sumba Tengah, Provinsi Nusa Tenggara Timur. Total jumlah SDM adalah sebanyak 21 orang termasuk pimpinan SKPD. Dapat dibayangkan antara kebutuhan dan tenaga yang ada belum dapat dikatakan atau masih jauh dari kata memadai sebagai suatu organisasi pelayanan kepada masyarakat di sektor pariwisata. Ditambah secara keahlian masih minim sarjana-sarjana sosial yang menekuni ilmu kebudayaan dan ilmu pariwisata sehingga dari sini dapat dikatakan secara kualitas pun sebenarnya SDM kantor Disbudpar Kabupaten Sumba Tengah, Provinsi NTT harus dibenahi kedepannnya.

Memang tidak dapat dipungkiri banyak hal yang harus dibenahi untuk dapat lebih mengoptimalkan peran masing-masing bidang di Disbudpar Kab. Sumba Tengah. Merupakan hal yang tidak mudah karena harus kembali mengacu kepada visi dan misi yang dimiliki, peraturan dan kebijakan serta situasi kondisi internal maupun eksternal yang terjadi.

Sebagai contoh betapa secara struktur dan fungsi masing-masing bidang harus mampu berkoordinasi dan saling memahami dengan tupoksi masing-masing bidang. Termasuk berkenan menerima kekurangan maupun kelebihan dari masing-masing bidang. Tanpa adanya saling pengertian antar bidang akan sulit menjaga stabilitas dan keharmonisan organisasi. Seperti Bidang Kesekretariatan jika tidak memahami kepariwisatan dalam arti sempit maupun dalam arti luas akan sangat sulit berkoordinasi dengan bidang pengembangan produk wisata misalnya. Begitu pula sebaliknya Bidang pengembangan produk wisata jika bersikeras dengan program kerja yang dimiliki adalah yang paling baik tanpa melihat kemampuan mata anggaran atau aturan/kebijakan yang menjadi bagian dari Kesekretariatan maka akan terjadi miss koordinasi yang tentu akan menghambat kinerja bidang-bidang lain sebagai satu kesatuan lembaga birokrasi pemerintahan.

Pimpinan struktur (dalam kasus ini adalah Kadisbudpar Kab. Sumba Tengah) harus menambah peran untuk menjaga stabilitas organisasi secara efektif dan efisien, selain begitu banyak peran yang diembankan berdasarkan Tupoksi. Sebagai penggerak atau komando dari SKPD Disbudpar, seorang Kadisbudpar Kab. Sumba Tengah memiliki beban tanggungjawab cukup berat yang harus selalu memahami kesulitan-kesulitan yang dihadapi bidang-bidang dalam melaksanakan tugasnya.

Disisi lain mulai dari Sekretaris, Kabid, Kasie hingga para staf dituntut pula kesadarannya untuk mampu menjalankan tugas 
dengan baik. Ketidak mengertian atau kekurang pahaman dalam penguasaan tugas yang dimiliki akan berpengaruh terhadap hasil (out put) kinerja dan akan berpengaruh pula terhadap apa yang diharapkan dari hasil tersebut dapat memberikan dampak positif (out come). Out come yang diharapkan tentu bersifat positif yang hanya dapat diperoleh jika peran masing-masing bidang di Disbudpar Kab. Sumba Tengah berjalan dengan baik.

Kesemua hal di atas akhirnya tidak terlepas dari kemampuan secara pribadi (psikologis) masing-masing individu baik pejabat maupun staf dan kemampuan secara sosialbudayanya untuk menerapkan tata kelola organisasi pemerintahan. Sebagai Pegawai Negeri Sipil (PNS), aparat Disbudpar Kab. Sumba Tengah adalah individu yang secara pribadi memiliki karakter berbeda antara satu dan lainnya serta memiliki kesamaan maupun perbedaan secara sosial-budaya. Karakter pribadi sebagai contoh adalah bersifat pemarah, pemalu, rajin, pemalas dsb. Kemampuan secara sosial-budaya contohnya adalah nilai-nilai budaya yang dianut termasuk faktor sosialnya seperti tradisi, kebiasaan, kesukuan, kesamaan dan perbedaan bahasa, agama, kepercayaan, strata sosial-ekonomi, dsb.

Jika dicermati kemampuan secara psikologis dan kemampuan secara sosial-budaya ditambah dengan kemampuan intelektual (yang diperoleh melalui akademis) sangat mempengaruhi aparat Disbudpar Kab. Sumba Tengah sebagai individu-individu yang diikat dalam satu kesatuan organisasi pemerintahan. Maka, untuk mendapatkan peran maksimal dari keseluruhan individu sebagai sebuah organisasi pemerintah individu-individu tersebut sebagai komponen dalam struktur Disbudpar Kab. Sumba Tengah harus mampu mengolah dan menyesuaikan karakter, sosial-budaya dan mengasah intelektual masing-masing. Kesadaran akan kebersamaan sebagai aparatur pemerintahan yang membidangi kebudayaan dan pariwisata menjadi tolak ukur untuk keberhasilan mencapai tujuan.

Akan lebih tepat jika kemampuan secara pribadi, kemampuan secara sosial-budaya dan kemampuan intelektual dapat dipahami sebagai tiga hal penting dalam suatu struktur sosial terutama dalam kasus Disbudpar Kab. Sumba Tengah. Pemahaman yang baik terhadap ke-3 hal penting ini akan mengantarkan kepada saling pengertian, saling menghormati, solidaritas, persaingan yang sehat, memiliki semangat korps pelaksana tugas pemerintah pada sektor budaya dan pariwisata dan meminimalkan terjadinya miss komunikasi atau yang terburuk adalah tidak berfungsinya suatu komponen dalam struktur tersebut. Pemahaman yang baik terhadap ke-3 hal penting di atas akan menempatkan peran pimpinan untuk dapat menempatkan aparatur sesuai dengan kemampuan yang dimiliki sehingga akan mempermudah dan memperlancar kinerja sesuai dengan sasaran dan target yang telah ditetapkan.

\subsection{Implementasi Strategi Pengembangan Pariwisata Dinas Kebudayaan dan Pariwisata Kabupaten Sumba Tengah}

Terdapat hal yang unik dalam impelementasi strategi pengembangan pariwisata oleh Disbudpar Kabupaten Sumba Tengah adalah minimnya program kerja untuk pengembangan SDM baik di lingkungan Disbudpar maupun masyarakat. Padahal di dalam Ripda Kab. Sumba Tengah dan Analisis SWOT yang telah dilakukan oleh Disbudpar Kab. Sumba Tengah jelas mencantumkan penguatan SDM sangat diperlukan dalam kepariwisataan di Kabupaten Sumba Tengah.

Permasalahan SDM di lingkungan Disbudpar Kabupaten Sumba Tengah dapat di atasi dengan memperhitungkan rasio kebutuhan pegawai dan terus diupayakan PNS yang berkompeten dalam sektor pariwisata baik secara pengalaman maupun secara akademis. Studi banding, Bimtek dan sejenisnya sangat menunjang kecakapan seorang PNS namun harus secara berkesinambungan dan diterapkan hasilnya. Termasuk penyuluhan-penyuluhan pariwisata di masyarakat dapat mengembangkan SDM, tetapi arah dan tujuannya harus terukur. Langkah strategis yang dapat diambil dalam waktu cepat adalah mengundang akademisi maupun praktisi pariwisata untuk secara rutin memberikan workshop atau sharing baik secara akademis maupun vokasional. SDM pariwisata dapat dibangun secara bertahap namun yang terpenting adalah harus berkesinambungan. Akan sangat terfokus jika Disbudpar Kabupaten Sumba Tengah menambah satu bidang kerja yaitu Bidang Sumber Daya Manusia (SDM) dan 
Kelembagaan Pariwisata untuk kebijakan dan fasilitator pengembangan SDM kedepannya.

Untuk Bidang kebudayaan dan bidang kesenian tampaknya memerlukan evaluasi untuk penjabaran program kerja yang tampaknya tumpang tindih. Kemungkinan disebabkan oleh kekosongan jabatan pada Kepala Bidang Kesenian menjadi permasalahan. Alangkah baiknya jika Bidang kesenian dijadikan satu dalam Bidang kebudayaan karena secara akademis kebudayaan mencakup kesenian (Koenjaraningrat, 1996). Selain efisiensi dan efektifitas penyatuan kedua bidang tersebut akan memudahkan untuk pelestarian dan pengembangan kebudayaan sebagai daya tarik wisata unggulan Kabupaten Sumba Tengah.

Bidang pemasaran dan penyuluhan pariwisata justru mulai dari misi, tujuan, sasaran, strategi dan arah kebijakan belum secara eksplisit menunjukkan pola pemasaran namun dalam renja baru terlihat pemasaran yang jumlah anggarannya cukup besar. Disamping itu pembuatan buku situs dan cagar budaya terlihat "dipaksakan" masuk dalam renja bidang ini yang seharusnya menjadi tugas dari Bidang Kebudayaan. Secara lebih khusus, aspek-aspek yang perlu diketahui dalam perencanaan dan pengembangan pariwisata adalah (Yoeti, 1999) :

1.Karakteristik Wisatawan

2.Fasilitas Transportasi

3.Atraksi Wisata

4.Fasilitas Pelayanan

5.Informasi dan Promosi

Bidang Pemasaran dan Penyuluhan Pariwisata belum menunjukkan langkah positif menuju pemahaman 5 komponen di atas. Akan lebih bijak jika dipahami fokus dari Bidang Kebudayaan dan Bidang Kesenian yang akan dipasarkan kepada wisatawan dipelajari dan dipasarkan. Target pasar seperti tipologi, karakteristik wisatawan, dan informasi/promosi belum mendapat perhatian khusus seperti upaya pendirian Tourist Information Centre (TIC). Satu hal menjadi catatan penting adalah perlunya menetapkan wisatawan mana yang akan berkunjung ke Kabupaten Sumba Tengah ditunjang oleh penguasaan informasi dan teknologi untuk pemasarannya.

Terakhir Bidang Pengembangan Produk Wisata memfokuskan kepada sarana dan prasarana lebih dari $90 \%$ anggarannya digunakan untuk itu. Hal ini wajar kemungkinan karena banyaknya fasilitas pariwisata yang tersebar yang perlu diperhatikan perawatannya atau kelengkapan infrastrukturnya. Mengingat begitu banyak tinggalan-tinggalan kebudayaan seperti rumah adat kuno yang harus diperhatikan. Disini tampaknya memerlukan pengkajian karena seharusnya yang memiliki tugas untuk tinggalan budaya (fisik) adalah Bidang Kebudayaan. Mengacu kepada Ripda Kabupaten Sumba Tengah alangkah baiknya jika kedepan Bidang Pengembangan Produk Wisata memiliki strategi untuk fokus kepada produk wisata.

Jika memungkinkan dibuatkan bidang Baru yaitu Bidang SDM Pariwisata. Bidang SDM Pariwisata akan mencakup SDM dari perspektif kebudayaan, kesenian, pemasaran dan penyuluhan pariwisata dan pengembangan produk wisata terutama dalam kaitannya secara eksternal Disbudpar Kab. Sumba Tengah yaitu meningkatkan pemahaman dan kemampuan masyarakat Kab. Sumba Tengah dalam rangka mempersiapkan SDM memadai untuk pembangunan kepariwisataan secara berkelanjutan, begitu pula Bidang Kebudayaan dan Bidang Kesenian sudah tepat mengangkat potensi yang dipilih maka harus diikuti oleh Bidang Pemasaran dan Penyuluhan Pariwisata untuk dipasarkan maupun dipromosikan sesuai dengan target pasar yang ditetapkan sebagai atraksi atau produk wisata. Sangat penting untuk mempelajari wisatawan seperti apa yang akan datang untuk dapat merencanakan akomodasi, fasilitas pendukung, fasilitas pelayanan dan penyediaan informasi dan promosi (berkaitan dengan bahasa dan Lintas Budaya). Penetapan pasar potensial wisatawan menjadi keharusan agar arah kebijakan, strategi, sasaran, tujuan dan misi pengambangan pariwisata tidak salah arah. Penetapan pasar wisatawan dapat diawali dengan pemahaman mengenai tipologi wisatawan dan secara empiris melihat destinasi wisata lain seperti Bali, Yogyakarta dan destinasi lainnya untuk dapat memberikan gambaran hubungan antara potensi, atraksi dan produk serta minat wisatawan domestik maupun mancanegara.

Aspek-aspek sepatutnya diidentifikasi sehingga akan memudahkan suatu daya tarik wisata menentukan product style. Penciptaan product style yang baik dalam pengembangan 
daya tarik wisata memiliki beberapa syarat yaitu (Yoeti, 1999) :

1. Objek atau daya tarik wisata harus menarik untuk disajikan maupun dipelajari

2. Mempunyai kekhususan dan berbeda dari objek atau daya tarik wisata lain

3. Prasarana menuju objek atau daya tarik wisata terpelihara dengan baik

4. Tersedia fasilitas wisata

5. Dilengkapi dengan sarana akomodasi, telekomunikasi, transportasi dan saranasarana pendukung lainnya.

Selanjutnya jika suatu daerah berkeinginan untuk mengembangkan pariwisata sebagai suatu industri maka perlu mengambil kebijaksanaan sebagai berikut (Yoeti, 1999) :

1. Menentukan secara tegas suatu keputusan apa tujuan pengembangan pariwisata di daerah tersebut

2. Memberikan beberapa pertimbangan ditinjau dari segi ekonomi, apakah keuntungan dari pembangunan pariwisata akan baikbagi daerah di mana kegiatan kepariwisataan itu dikembangkan maupun bagi perekonomian secara keseluruhan

3. Bila telah sampai pada suatu kesimpulan bahwa pariwisata penting bagi suatu daerah maka dipersiapkan suatu studi tentang pengembangan yang akan diadakan berikutnya dengan memperhatikan pasar potensial yang diharapkan dari mana wisatawan akan datang.

Dengan tidak bermaksud mengesampingkan strategi pengembangan yang telah dilakukan Disbudpar Kabupaten Sumba Tengah tampak belum mengembangkan product style dalam hal ini wisata budaya dan wisata alam secara maksimal karena sebaran dan bervariatif. Akan sangat efektif jika dipilih satu product style pada satu lokasi yang mampu menjadi daya tarik wisata unggulan yang dapat dipadukan bersama atraksi dan produk wisata lainnya. Sebagai contoh kain tenun Sumba yang memiliki ciri khas dapat dipadukan dengan kesenian tradisional lokal dan hasil pertanian/perkebunan seperti jambu mente, kacang kapri atau lainnya yang merupakan hasil pertanian/perkebunan lokal yang diminati wisatawan.
Dari hasil penelitian di atas terungkap selain permasalahan SDM, aksesibilitas, akomodasi dan pemasaran pariwisata yang minim, tentunya permasalahan pengelolaan dan peran pemerintah kabupaten yang minim sebagai fasilitator menjadi salah satu faktor utama sulitnya pengembangan sektor pariwisata. Solusi termudah dan tercepat adalah Kabupaten Sumba Tengah melalui Disbudparnya harus memaksimalkan peran dan mengevaluasi fungsi masing-masing bidang dalam mempercepat pembangunan pariwisata.

Hal tersebut dapat diikuti dengan konsolidasi dan koordinasi bersama SKPD-SKPD se-Kabupaten Sumba Tengah. Seperti SKPD Perhubungan (LLAJ) yang berhubungan dengan aksesibilitas, SKPD Pertanian dan Perkebunan berkaitan dengan hasil-hasil pertanian yang dapat dijual kepada wisatawan, SKPD Perindustrian dan Perdagangan terkait dengan pengembangan usaha kecil (UMK dan UMKM) untuk memperkuat sektor industri seperti handycraft, kain khas Sumba, SKPD Koperasi untuk memberikan penguatan ekonomi dari bawah sehubungan dengan pengembangan industri dan jasa pariwisata. Termasuk juga SKPD-SKPD lain harus memiliki pemahaman yang sama dan harmonis mengenai pariwisata. Sehingga Ripda Kabupaten Sumba Tengah dapat di pahami sebagai acuan secara sinergis dan holistik.

Sebagai sebuah sistem birokrasi peran Bupati sebagai Kepala Daerah Sumba Tengah sangat strategis untuk mencapai keberhasilan pembangunan pariwisata. Visi dan misi kepala daerah jika menginginkan pengembangan pariwisata secara berkelanjutan di Kabupaten Sumba Tengah tidak dapat hanya menugaskan Disbudpar Kabupaten Sumba Tengah. Melainkan harus mampu menciptakan pola koordinasi dan hubungan lintas SKPD agar pengembangan pariwisata dapat dilakukan secara bertahap dan terfokus. Proses pasti diperlukan dalam hal ini, tidak dapat mengharapkan hasil dalam waktu yang cepat. Selain itu, kepala daerah dapat membangun jaringan bersama kabupaten seProvinsi NTT untuk dapat menangkap pasar potensial yang akan saling melengkapi. 


\section{PENUTUP}

\subsection{Kesimpulan}

Berdasarkan hasil penelitian yang telah dilakukan maka diperoleh simpulan sesuai dengan rumusan permasalahan sebagai berikut :

1. Peran Dinas Kebudayaan dan Pariwisata dalam Pembangunan Pariwisata di Kabupaten Sumba Tengah, Provinsi Nusa Tenggara Timur (NTT) dilaksanakan sesuai dengan tugas pokok dan fungsi (Tupoksi) yang diamanatkan oleh Kepala Daerah Kabupaten Sumba Tengah. Terdapat 4 bidang di Dinas Kebudayaan dan Pariwisata (Disbudpar) Kabupaten Sumba Tengah, Provinsi NTT yang wajib melaksanakan tugas memberikan pelayanan sektor kepariwisataan sesuai dengan potensi dan rencana pengembangan pariwisata Kabupaten Sumba Tengah yaitu Bidang Kebudayaan, Bidang Kesenian, Bidang Pemasaran dan Penyuluhan Pariwisata dan Bidang Pengembangan Produk Wisata. Permasalahan yang dihadapi dalam penjabaran tupoksi adalah kemampuan secara pribadi, kemampuan secara sosialbudaya dan kemampuan intelektual aparatur di Disbudpar Kab. Sumba Tengah, Provinsi NTT, kedepan harus menjadi pertimbangan untuk kinerja yang efektif dan efesien dalam suatu organisasi pemerintahan yang harmonis.

2. Implementasi Strategi Pengembangan Pariwisata Dinas Kebudayaan dan Pariwisata Kabupaten Sumba Tengah dilihat dari misi, tujuan, sasaran, strategi, arah kebijakan dan rencana kerja masingmasing bidang yaitu Bidang Kebudayaan, Bidang Kesenian, Bidang Pemasaran dan Penyuluhan Pariwisata dan Bidang Pengembangan Produk Wisata sudah menunjukkan kemauan yang kuat dari Disbudpar Kab. Sumba Tengah untuk mewujudkan pembangunan kepariwisataan secara serius. Hanya dalam implementasi strategi pengembangan pariwisata tersebut, masih terdapat beberapa hal yang patut dicermati untuk mewujudkan pembangunan pariwisata yang tepat sasaran di kemudian hari. Terjadi kesulitan SKPD Disbudpar Kabupaten
Sumba Tengah mengacu kepada Rencana Induk Pembangunan Pariwisata Daerah (Ripda) Kab. Sumba Tengah 2013-2028 dan menerjemahkan analis SWOT SKPD Disbudpar Kabupaten Sumba Tengah 2014-2019. Faktanya adalah kerancuan fokus sasaran dalam rencana kerja masing-masing bidang, sumber daya manusia (SDM) secara kualitas dan kuantitas, fokus pemasaran yang belum menetapkan product style dan pasar potensial wisatawan, dan belum terlihat koordinasi dengan SKPD-SKPD lain sekabupaten Sumba Tengah sehingga pembangunan pariwisata dilihat dari implementasi strategi pengembangan pariwisata masih bersifat partial.

\subsection{Saran}

Dari kesimpulan di atas, maka beberapa saran yang dapat disampaikan kepada Dinas Kebudayaan dan Pariwisata (Disbudpar) Kabupaten Sumba Tengah, Provinsi Nusa Tenggara Timur (NTT) adalah :

1. Penambahan SDM secara kualitas maupun kuantitas di lingkungan SKPD Disbudpar Kabupaten Sumba Tengah,Provinsi NTT.

2. Pertimbangan membentuk Bidang SDM Pariwisata.

3. Bidang Kesenian Disbudpar Kabupaten Sumba Tengah dipertimbangkan menjadi bagian dari Bidang Kebudayaan untuk efisiensi dan efektifitas kinerja

4. Evaluasi Bidang Pemasaran dan Penyuluhan Pariwisata agar dalam rencana kerja fokus kepada pemasaran dan penyuluhan pariwisata

5. Bidang Pengembangan Produk Wisata diupayakan berkoordinasi lintas bidang dan lintas SKPD untuk fokus terhadap beberapa objek wisata (tidak lebih dari 3 lokasi), sehingga dalam pembangunan sarana-prasarana tidak menyebar dan beresiko pemborosan anggaran.

6.Segera menetapkan pasar potensial wisatawan dan product style untuk lebih mengarahkan misi, tujuan, sasaran, strategi, arah kebijakan dan rencana kerja kedepan.

7.Sosialisasi Ripda kepada seluruh SKPD di Kabupaten Sumba Tengah 
8. Mengadakan rapat koordinasi antara SKPD tentang pembangunan pariwisata per triwulan.

\section{DAFTAR PUSTAKA}

Anonim. 2001. Kamus Besar Bahasa Indonesia. Departemen Pendidikan Nasional. Jakarta : Balai Pustaka

Anonim. 2005. Undang-undang Republik Indonesia No.32 Tahun 2004 tentang Pemerintah Daerah.

Anonim. 2005. Undang -Undang Otonomi No.23 tahun 2004 tentang Pemerintah Daerah

Anonim. 2014. Renstra Kab. Sumba Tengah 2014-2019. Waikabul : Disbudpar Kab. Sumba Tengah

Anonim. 2014. Riparda Kab. Sumba Tengah. Waikabul : Bappeda Kab. Sumba Tengah

Arikunto, S. 2010. Prosedur Penelitian Suatu Pendekatan Praktik Edisi Revisi. Jakarta :

Rineka Cipta.

Bungin, Burhan. 2003. Metode Penelitian Kualitatif. Jakarta : PT. Raja Grafindo Persada.

Denzin Norman dan Lincoln Yvona S. 2009. Handbook Qualitative Research.

Yogyakarta : Pustaka Pelajar

Labolo, Muhadam. 2006. Memahami Ilmu Pemerintahan (Suatu Kajian, Teori, Konsep dan Pengembangannya). Jakarta : Raja Grafindo Persada.

Moleong, Lexy J. 2005. Metode Penelitian Kualitatif. Bandung : Remaja Rosdakarya

Pendit, S.2006. Ilmu Pariwisata, Sebuah Pengantar Perdana. PT. Pradnya Paramita, cetakan ke- delapan (edisi revisi) Jakarta.

Pitana, I Gde dan Gayatri, Putu G. 2005. Sosiologi Pariwisata. Penerbit Andi :

Yogyakarta

Pitana \& Diarta. 2009. Pengantar Ilmu Pariwisata. Yogyakarta : Andi Offset.

Purwanto, Iwan. 2012. Manajemen Strategi. Bandung : Yrama Widya

Marpaung dan Bahar, 2000. Definisi Pariwisata. Bandung : Alfa Beta

Soekanto, Soerjono. 2001. Sosiologi Suatu Pengantar. Jakarta : PT. Raja Grafindo Persada. UU Otonomi No.22 tahun 1999 tentang Pemerintah Daerah 